\title{
Dynamic Asset Allocation Using Systematic Sector Rotation
}

\author{
Paolo Sassetti and Massimiliano Tani
}

December 2003

\begin{abstract}
This paper uses the insight that the sectors composing the economy perform differently and (to a certain extent) independently one another over the phases of the economic cycle to explore the existence of investment rules capable of exploiting such dynamics and over-perform market returns. The analysis uses three simple market-timing techniques on 41 funds of the Fidelity Select Sector family over the period January 1998-September 2003. The results indicate that each technique can exploit the pathdependency of the returns across sectors, and consistently over-perform the return of a buy-and-hold strategy. It is hoped that these results will encourage investors, investment managers, and academics to further investigate some of the heuristic models successfully used by practitioners.
\end{abstract}

Key Words: Capital market efficiency, portfolio theory.

Dr Massimiliano Tani

School of Economics and Management

University of New South Wales at the

Australian Defence Force Academy

Northcott Drive

Campbell ACT 2606

Australia

Tel.: + 61262688512

Fax: + 61262688450

E-mail: m.tani@adfa.edu.au
Dr Paolo Sassetti

Rivista Aiaf (Review of the Italian Financial Analysts)

Member of the Scientific

Committee

Via Pertini, 32,

20040 Carnate (Milano) Italy

Tel.: +390396076137

Mobile: +39 3283131671

E-mail: p.sassetti@tin.it 


\section{Introduction}

The financial markets' downturn of the period 2000-2002 has tested a number of investment strategies, and raised (again) the question on whether one can devise a rule, if at all, to achieve returns above market indices whilst protecting the capital invested. The results obtained by investment funds during 2000-2002 suggest that passive and semi-passive investment strategies can not protect investors against the negative effect of a prolonged period of poor economic conditions. At the same time, the alternative offered by active investment strategies, which is based on the idea of selecting specific stocks or asset classes, has obtained mixed results. If on the one side REITs and funds specialised in precious metals have been able to keep up their value at times of falling market indices, on the other side they have not kept pace with the rise of technology stocks in early 2003. As investors, are we really stuck in choosing between a passive investment strategy and an active diversification through asset classes within or across countries? We do not think so, and in this paper we present the results of a series of simulations that use systematic rotation among equity sectors as a tool for dynamic asset allocation performed on US data for the period 1998-2003. Our aim is not to say that we found the system to 'beat the market', but to encourage investors, academics and fund managers to question some of the assumptions commonly used in investment management, and investigate with more rigour some of the heuristic methods used by practitioners.

\section{Systematic sector rotation: a brief review}

The idea that different sectors benefit differently from the phases of the economic cycle, and therefore that the prices of some sector indices could move independently of others along their paths, is not new. Surprisingly, however, this insight seems to have limited application in portfolio management. Existing work focuses on the limited correlation between the market as a whole and individual asset classes (e.g. stocks, real estate, bonds, cash) or stocks, or between national markets. Systematic sector rotation is based on the idea that the sectors composing the economy do not follow the same patterns over time, but move differently one another [Stovall, 1996]. Two main reasons seem to underpin this behaviour. The first is the presence of fundamentals. Some sectors benefit relative to others during the growth phases of the 
economy (e.g. hotel and leisure) whilst other sectors are relatively better off when the economy is in decline (e.g. tobacco). The second reason is psychological, and it reflects investors' beliefs about a sector's future performance relative to another or a momentarily fashion. Hence, at each point of the economic cycle there are sectors that have more chances than others to generate an extra return (or hold value) relative to other sectors, or that are reputed to achieve this result. Systematic sector rotation aims at switching the portfolio regularly so as to capture at least part of the extra returns that different sectors experience relative to the rest of the market. The ability to identify current and next 'hot themes' would give investors the possibility of overperforming the market.

As suggested by Fowler [1997], the critical issue in dynamic asset allocation is to define the guiding rule to identify ex ante the rotation criteria to follow for switching amongst sectors. Since this guiding rule in discretionary portfolio management is typically subjective, it is open to question. Hence institutional investors tend to avoid using dynamic investment strategies, preferring to invest in a predefined mix of asset classes managed by specialists whose performances are measured against specific benchmarks ${ }^{1}$.

Market-timing techniques are a simplified form of dynamic asset allocation that are popular amongst individual investors, and include only two asset classes: shares and cash. Given their simplified nature, they should be less open to interpretation. One would therefore expect to see them commonly used amongst professional fund managers, though this does not seem to be the case. The reasons for the modest popularity of these techniques in professional portfolio management can be summarised as follows:

1. market-timing techniques are heuristic with none of the formal rigour of optimisation models. Hence they have never enjoyed the favour of academics,

\footnotetext{
${ }^{1}$ This investment strategy therefore gives priority to strategic asset allocation (where the portfolio is periodically adjusted to the original weights by selling winners and buying losers), in sharp contrast with tactical asset allocation (minor changes in asset class weights based on predicted relative return) and dynamic asset allocation (where major changes in weights are possible).
} 
who traditionally preferred using optimisation techniques despite their most notable limitations, such as the reliance on static models of the past rather than dynamic representations of the present;

2. given their heuristic rather than scientific nature, these models are tied to the ability, creativity, intuition of their individual developers. Therefore, their adoption is at odds with rigid organisational structures and management styles, typical of large investment firms;

3. market-timing techniques have typically only two dimensions of the investment: price and time. However, they leave aside the selection of the asset class, which is normally predetermined. The application of market-timing uses computerised trading systems, which normally define when and how much a fund manager can be positioned on a specific market, though they do not specify which market or asset class to choose. This limitation compromises the criterion of optimum that institutional investors set to their fund managers ("who says that these markets are the most promising/trending at any time?');

4. last but not least, when markets consistently rise with few limited and sudden falls, as from the early 1980s to 2000, market-timing techniques have performed worse than buy \& hold strategies. Institutional investors rarely use market-timing techniques, and when so they use them for the purpose of insuring the investment against the possibility of disastrous losses rather than for the belief that they may over-perform the market under any conditions.

Despite these limitations, the dynamic nature of the capital markets and the possibility of new prolonged falls in the stock market indices, suggest that institutional investors might consider introducing more flexibility, adaptability and readiness to change in their current practices.

\section{An application of systematic sector rotation}

In this section we present an application of systematic sector rotation based on heuristic techniques of sector momentum. Our aim is to verify whether simple ex ante 
guiding criteria for switching sectors yield returns consistently above those of the benchmark. Methodologically, this analysis is equivalent to expand systematic management to add a third dimension beyond time and price: sector asset class.

To better illustrate what we did, consider the four figures depicted below. Figures $1(a)-1(d)$ represent the proportional change experienced by nine 'macro'-sectors of the Amex in the 180, 90, 65 and 30 days before $5^{\text {th }}$ September 2003, respectively. These charts were obtained from www.stockcharts.com. The nine sector aggregations are: Cyclicals and Transport, Technology, Industrials, Materials and Basic Industry, Energy, Consumer Staples, Services, Utilities, and Financials.

Figure 1 Percentage change in the value of nine macro-sectors of Amex as of $5 / 11 / 2003$

(a) relative to the previous 180 days

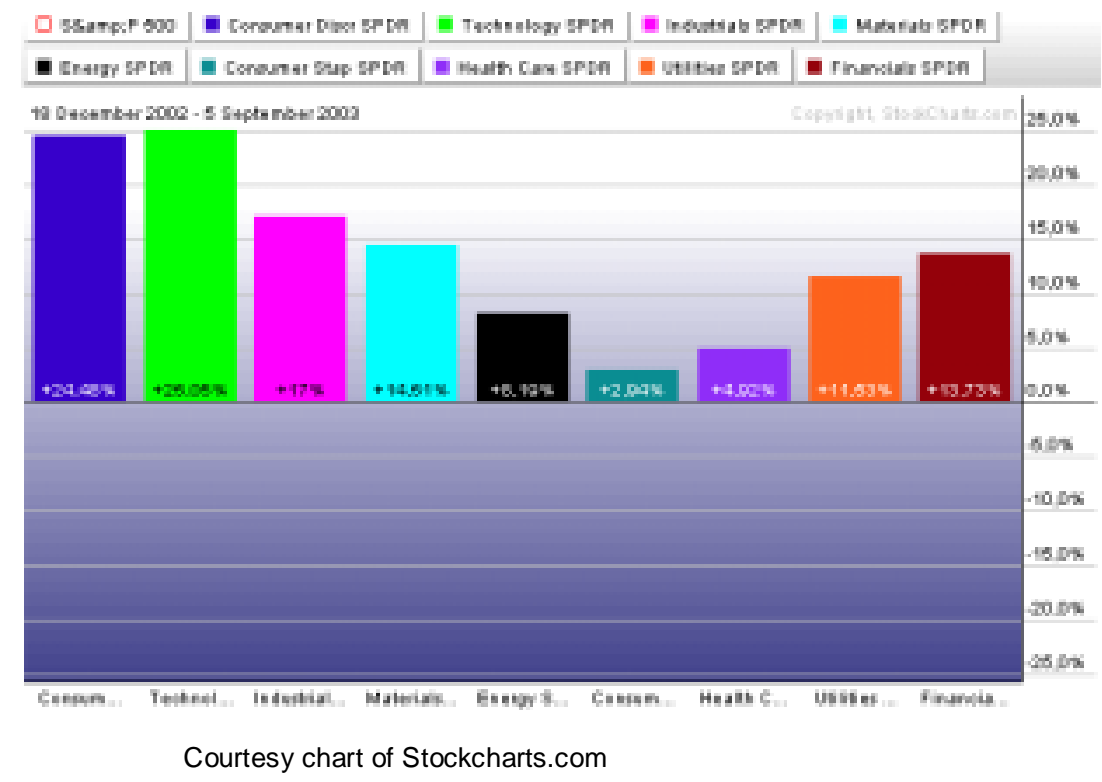


(b) relative to the previous 90 days

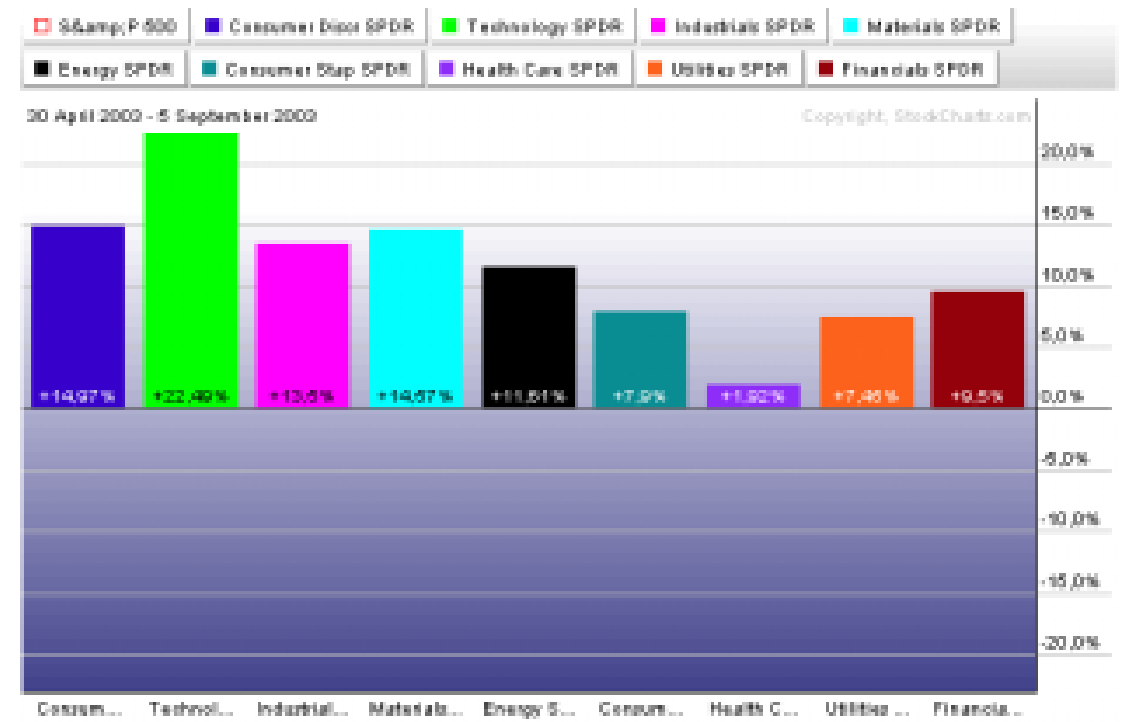

Courtesy chart of Stockcharts.com

(c) relative to the previous 65 days

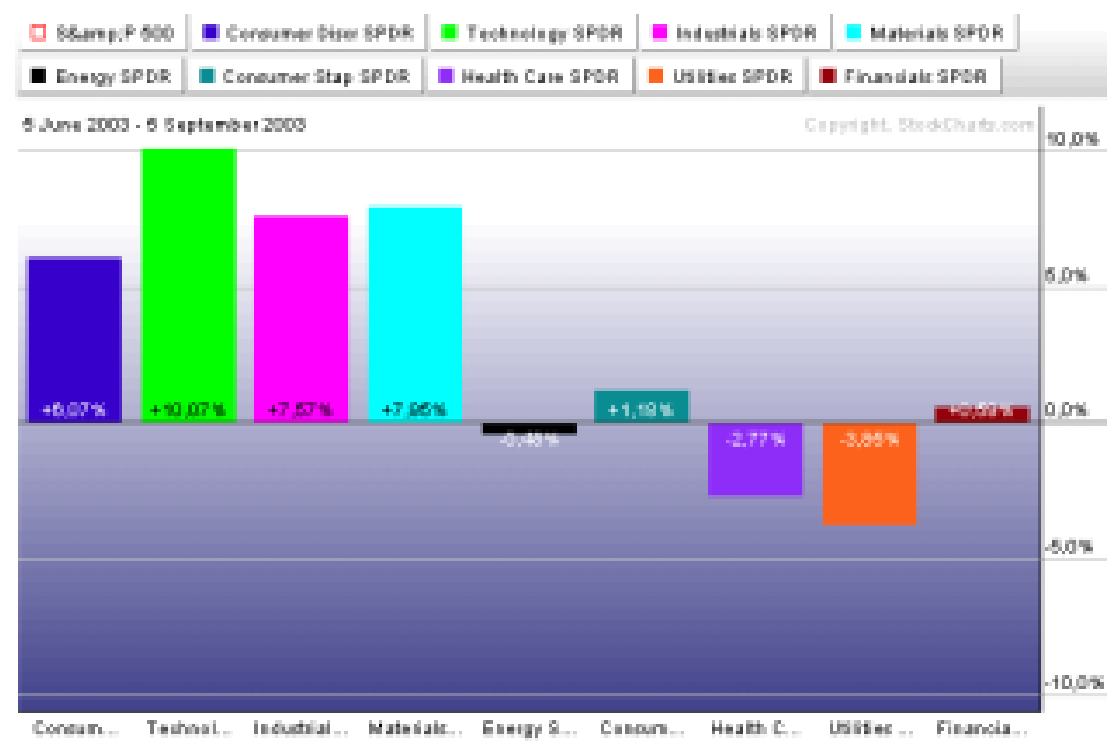

Courtesy chart of Stockcharts.com 
(d) relative to the previous 30 days

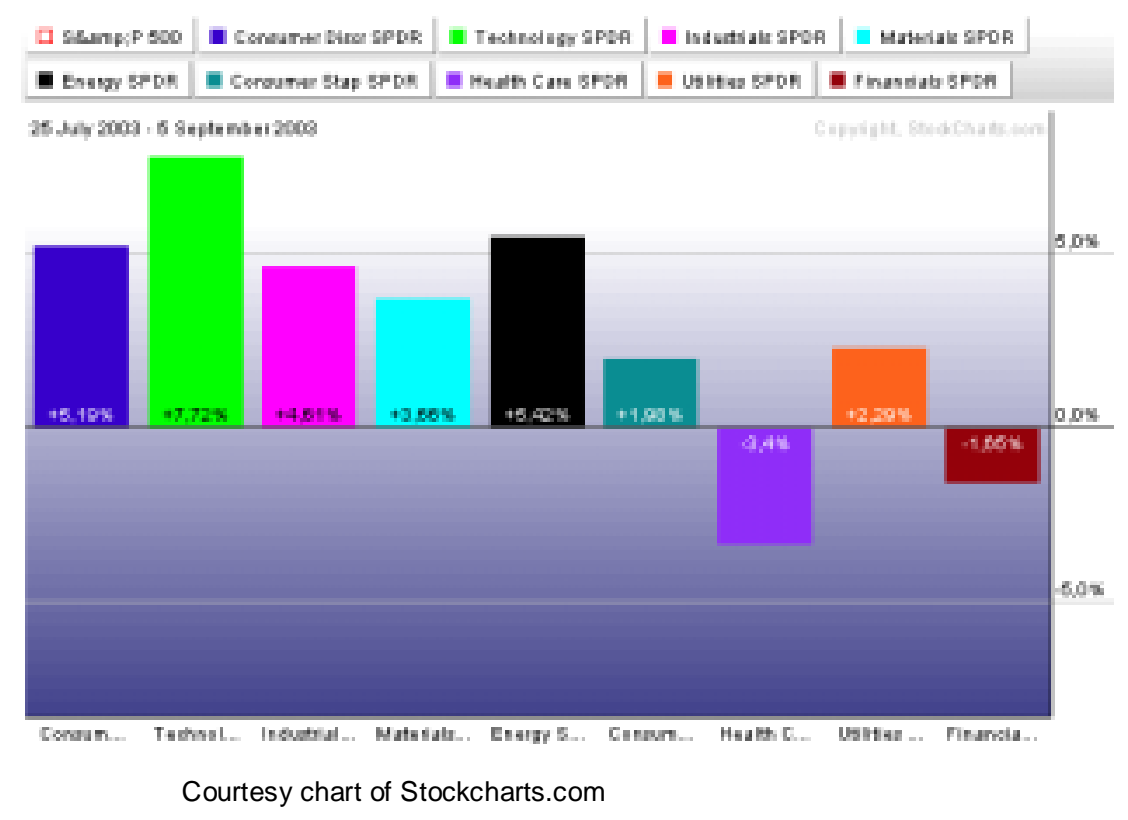

As shown in Figures 1(a)-1(c), the first four macro-sectors experienced the highest percentage increase in value during the 180 days, 90 and 65 days before $5^{\text {th }}$ September 2003, respectively. In contrast, Figure $1(d)$ reveals that in the 30 days prior to $5^{\text {th }}$ September 2003 a new 'theme' had emerged: Energy. The analysis of Figure 1(a)$1(d)$ suggests the existence of path-dependence (a sort of sector memory) in the returns of the macro-sectors. Such path-dependence drives, at least for a little while, the subsequent over-performance of these sectors relative to the other macro-sectors. This example is indicative of the fact that price movements across sectors do not seem to follow a chaotic path. In contrast, they seem to evolve over fairly defined trends.

Next, we wanted to verify empirically whether this phenomenon could be exploited in practice (and not only recognised ex post), to obtain a total return above that of the S\&P 500, which we used as a benchmark. Again, this idea is not new. In the early 1980s, Gil Blake, a trader who became famous for developing trading systems on mutual funds, noticed that although individual stocks and funds followed a random behaviour on a day by day basis, some sector funds had a higher probability (about $70-80 \%$ ) to perform in the same direction for some days after a particularly anomalous daily change. As he said: “..assume you have 99 chemical stocks which on 
average are up 1 or 2 percent today, while the broad market is flat. In the very short run, this homogenous group of stocks tends to behave like a school of fish. While the odds of a single chemical stock being up tomorrow may be $55 \%$, the odds for the entire chemical group are much closer to 75\%" [Schwager, 1992].

Later, Harloff [1998] showed that a strategy of dynamic switching amongst uncorrelated asset classes (precious metals, long and short term bonds, sector funds, growth funds, international funds, etc.) based on relative strength momentum was very successful in terms of higher compound return and Sharpe ratio relative to a benchmark composed of aggressive growth funds.

More recently, King, Silver and Guo [2002] have suggested that the long-term persistence in asset class index returns may be captured in order to enhance portfolio risk and return vis-à-vis buy-and-hold and constant mix strategies.

Consistently with Blake's original insight, we simulated investing in the US market using sector rotation as a dynamic investment device, and we did so for a longer period of time. The simulations were run on US market data covering the period between $1^{\text {st }}$ January 1998 and $18^{\text {th }}$ September 2003. This period includes a market characterised by a 'bull', a 'distribution', a 'bear' and a second 'bull' trend, therefore covering a complete market cycle. We simulated our strategy using 41 sector funds from the Fidelity Select Sector family ${ }^{2}$.

\section{Empirical results}

The first set of empirical results was obtained by fully investing in the Fidelity funds. In particular, we simulated to invest in the first $1,2,3 \ldots, 10$ and all the 41 funds of the series Fidelity Select Sector picking, as a selection criteria, the funds with the

\footnotetext{
2 They were: Air Transports, Automotive, Banking, Bio-technologies, Brokerage and Investment, Chemicals, Computers, Consumer Products, Construction and Housing, Defence and Aerospace, Developing Communications, Electronics., Energy Services., Energy, Environmental Services, Financial Services, Food \& Agriculture, Gold, Health Care, Home Finance, Industrial Equipment, Industrial Materials, Insurance, Leisure, Medical Delivery, Multimedia, Natural Gas, Paper \& Forest, Retailing, Software and Computer Services, Technology, Telecommunications, Transportation, Utilities Growth.
} 
highest relative strength in the previous 30, 60 and 90 days. The relative strength was calculated using three different indicators, namely:

1. the Rate of Change calculated for each fund in the previous 30,60 and 90 days. This indicator is a simple measure of price 'speed' in the chosen time frame;

2. the Alpha of the Capital Asset Pricing Model, calculated for each fund using the same time frame. This indicator represents a risk-adjusted return of a fund relative to the market index;

3. the Relative Strength of each fund with respect to the S\&P 500. Specifically, the relative strength of each fund over the S\&P 500 was computed using its moving average calculated over a period of 180 days and then over 3 shorter periods (30, 60 and 90 days). The difference between each of the three shorter moving averages and the one calculated on 180 days was interpreted as the Relative Strength of the fund.

The timeframes of 30, 60 and 90 days have been chosen purely on the basis of heuristic criteria, with no optimisation algorithm. We simply assumed that our investments in each fund were held for at least 30 days in order not to incur in the switch commissions applied by Fidelity for shorter holding periods (recently Fidelity has announced the removal of the front-end load for the Select Sector fund family we used in our simulations). Obviously the minimum holding period of 30 days is not an optimal condition. Nor did we not apply the stop loss and trailing stop features to avoid adding more structure and interferences in the 'natural' dynamics of sector rotation to the preliminary simulations we wanted to perform, which are presented below. This simplified approach was chosen to avoid the risk of over-fitting the sector rotation criteria we followed, and to have an unrefined and raw computational output against which future work, based on more sophisticated algorithms, can be referred to.

Our first result indicated that by investing an equal amount in each of the 41 funds of the Fidelity Select Sector family at the beginning of January 1998, the resulting portfolio performance at the end of the period would have been $37 \%$. The corresponding performance of the S\&P 500 was 7\%. Hence, between 1998 and 2003, the Fidelity Select Sector family of funds experienced an additional 30\% returns above that of the S\&P 500. It is difficult to believe that all of the extra-performance 
achieved using sector rotation can be attributed to this strategy. Part of the strategy over-performance may be attributed to the high relative strength (on the average) of the family of funds we used in our tests. Each of the sections below describes the results of the simulations obtained following each of the criteria described above.

\subsection{Using the Rate of Change}

The selection of funds based on the Rate of Change in the previous 30, 60 and 90 days, respectively, yielded the following performance.

Table 1 - Total return of a sector rotation strategy based on the Rate of Change indicator

\begin{tabular}{cccc}
$\begin{array}{c}\text { Number } \\
\text { of funds }\end{array}$ & $\begin{array}{c}\mathbf{3 0} \text { days } \\
\text { R.o.C. }\end{array}$ & $\begin{array}{c}\mathbf{6 0} \text { days } \\
\text { R.o.C. }\end{array}$ & $\begin{array}{c}\mathbf{9 0} \text { days } \\
\text { R.o.C. }\end{array}$ \\
\hline 1 & $156 \%$ & $-10 \%$ & $-5 \%$ \\
2 & $86 \%$ & $95 \%$ & $78 \%$ \\
3 & $37 \%$ & $\mathbf{2 1 5} \%$ & $84 \%$ \\
4 & $64 \%$ & $148 \%$ & $101 \%$ \\
5 & $66 \%$ & $148 \%$ & $132 \%$ \\
6 & $69 \%$ & $144 \%$ & $121 \%$ \\
7 & $80 \%$ & $120 \%$ & $89 \%$ \\
8 & $49 \%$ & $96 \%$ & $88 \%$ \\
9 & $72 \%$ & $110 \%$ & $99 \%$ \\
10 & $52 \%$ & $110 \%$ & $99 \%$ \\
& & & \\
41 & $37 \%$ & $37 \%$ & $37 \%$
\end{tabular}

Table 1 indicates that choosing a reduced number of sector funds where to invest at the same time (1-2) does not appear to yield the best returns, possibly because of the noise signals that characterise the funds with high volatility. The noise leads to exiting from such funds prematurely after to a sudden fall in prices. The highest return is highlighted in bold in the table, and was obtained following the Rate of Change calculated on the previous 60 days, keeps positions simultaneously in 3 sector funds, carrying out on average 26 trades each year, of which $62 \%$ yielded a profit. The relatively high proportion of trades incurring a loss (38\%) is neither surprising nor particularly significant as the model cannot short-trade, and it was always been fully invested throughout the period. 


\subsection{Using the Alpha indicator}

The results following a sector rotation based on the Alpha indicator using the same timeframe (30, 60, and 90 days respectively) is reported in Table 2.

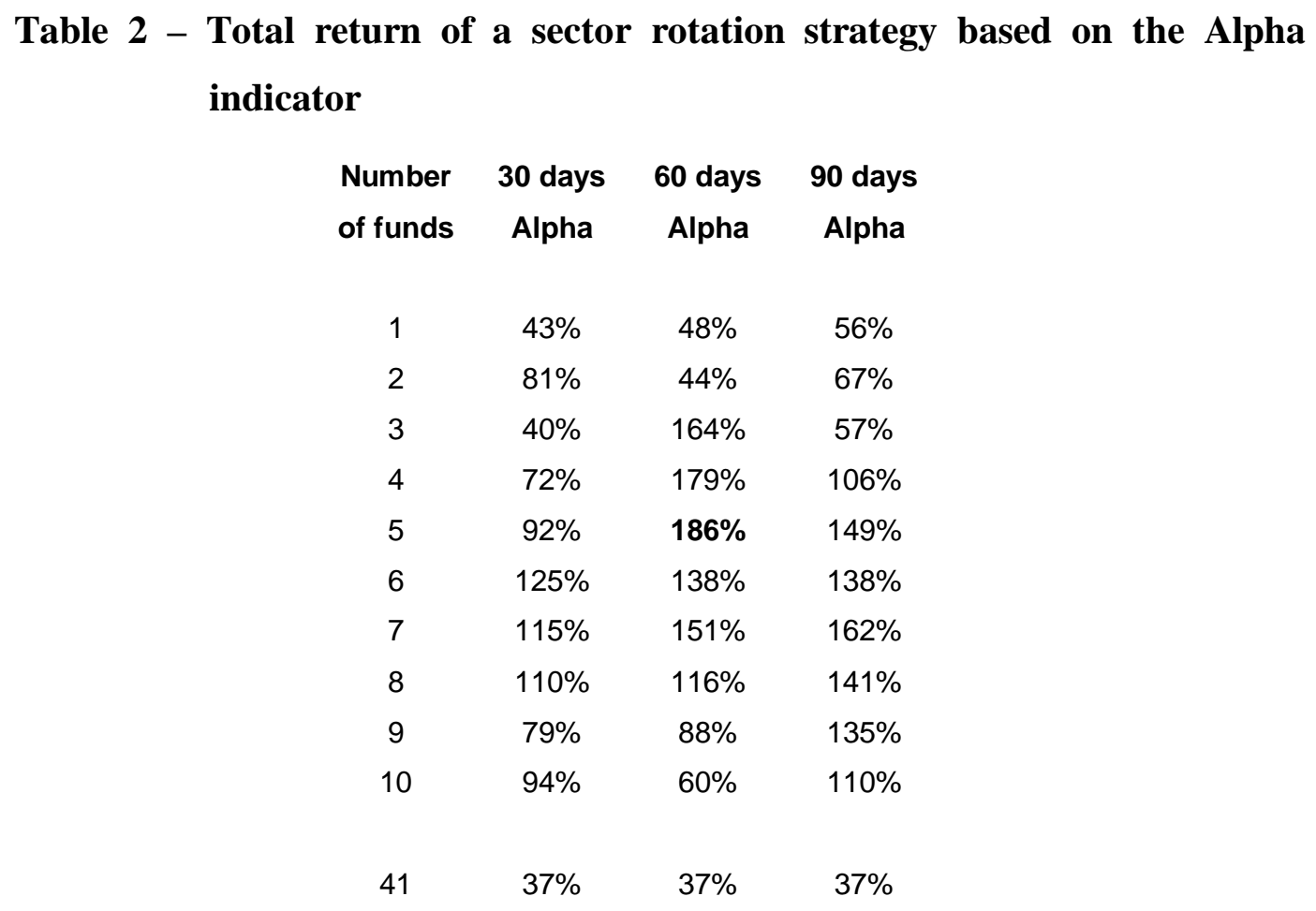

The results presented in Table 2 appear more regular and stable than those obtained using the Rate of Change. The best total return, highlighted in bold, was obtained using the Alpha indicator calculated on the previous 60 days, 5 funds, and 42 trades per annum, of which $56 \%$ yielded a profit.

One interesting feature is that with both the Alpha indicator and the Rate of Change, the over-performance relative to the benchmark rises with the number of the funds invested, peaks when the number of funds is between 3 and 7 , and declines thereafter (see Figure 5). At the same time, the relative strength line of the equity curve relative to the benchmark (see later) becomes smoother as the number of funds invested peaks to the optimal number. Hence, the extra performance of the rotational strategies seems to become more stable and regular over time. This pattern suggests that sector rotation over-performs the benchmark during speculative phases and 'administers' such gains in subsequent periods, accepting some periods of limited under-performance. 
Figure 5 Distribution of total returns of the sector rotation model based on the Alpha indicator

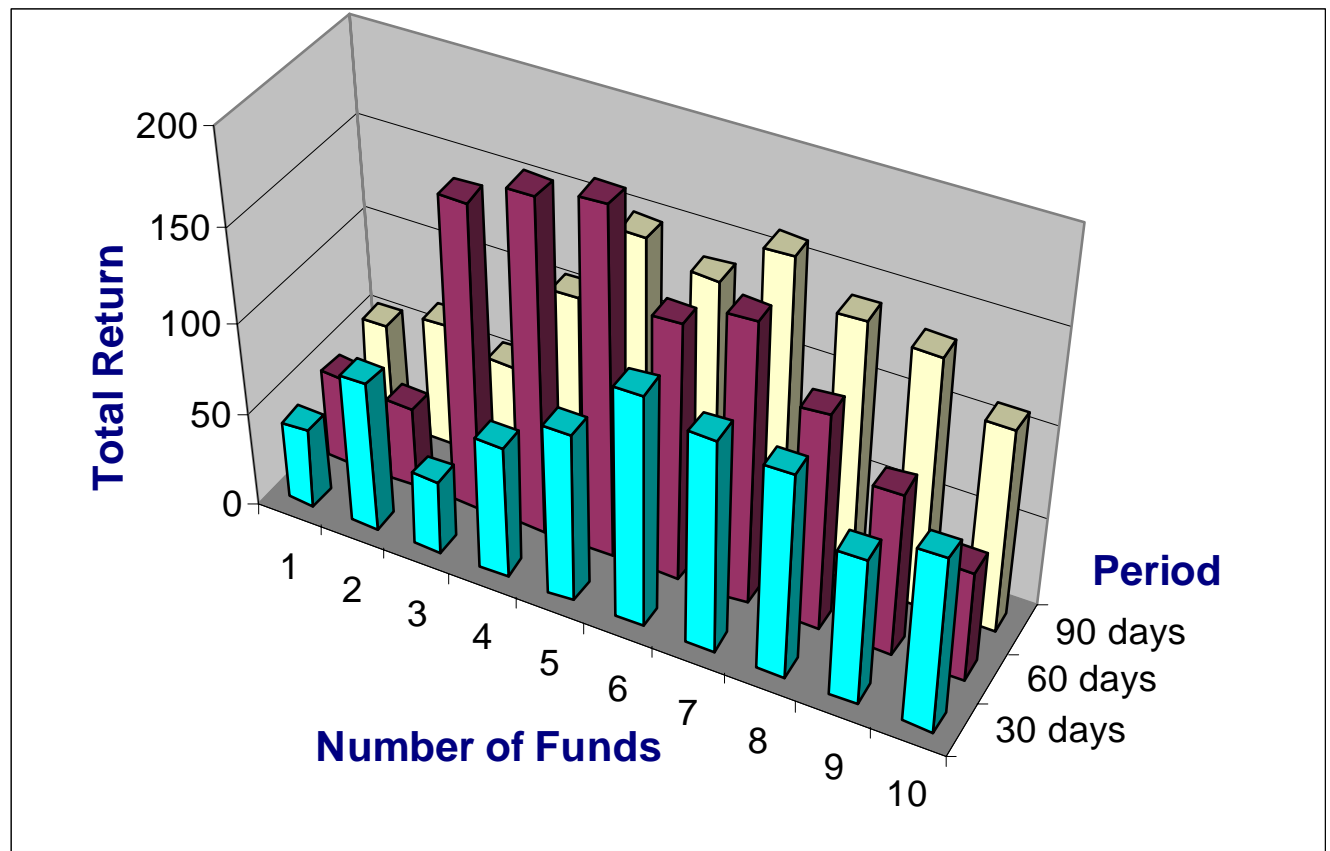

\subsection{Using the MACD}

The results obtained when sector rotation follows the MACD indicator (Moving Average Convergence Divergence) calculated over the previous 30, 60 and 90 days relative to the S\&P 500 is shown in Table 3.

This simulation has yielded the most reliable returns amongst those examined so far, in the sense that their distribution 'almost' follows the shape of a normal distribution which we take as indicating the absence of extremely high spikes in the distribution of total returns. This result may be due to the fact that the MACD index captures the strongest and most lasting intermediate sector trends ${ }^{3}$. The best performance test was obtained on the Relative Strength indicator calculated over the previous 90 days, using 5 funds, generating on average 15 trades each year, which yielded a profit only $52 \%$ of the times.

\footnotetext{
${ }^{3}$ Some of the highest gains achieved on specific trades of the best test (in bold) were: $238 \%$, obtained by holding the Technology fund from $13^{\text {th }}$ November 1998 to $21^{\text {st }}$ June 2000; $198 \%$ obtained by holding the Electronics fund from $10^{\text {th }}$ December 1998 to $19^{\text {th }}$ September 2000, $178 \%$ obtained by holding the Computers fund from $8^{\text {th }}$ September 1998 to $20^{\text {th }}$ January 2000 ,
} 
Table 3 - Total return of a sector rotation strategy based on the Moving Average Convergence Divergence indicator on Relative Strength (slower moving average $=\mathbf{1 8 0}$ days)

$\begin{array}{cccc}\text { Number } & 30 \text { days } & 60 \text { days } & 90 \text { days } \\ \text { of funds } & \text { Rel.Str. } & \text { Rel.Str. } & \text { Rel.Str. }\end{array}$

$\begin{array}{cccc}1 & -4 \% & 63 \% & 143 \% \\ 2 & 121 \% & 111 \% & 106 \% \\ 3 & 121 \% & 103 \% & 204 \% \\ 4 & 143 \% & 150 \% & 190 \% \\ 5 & 117 \% & 174 \% & \mathbf{2 3 8 \%} \\ 6 & 185 \% & 187 \% & 215 \% \\ 7 & 158 \% & 207 \% & 198 \% \\ 8 & 137 \% & 165 \% & 181 \% \\ 9 & 157 \% & 196 \% & 172 \% \\ 10 & 146 \% & 184 \% & 188 \% \\ & & & \\ 41 & 37 \% & 37 \% & 37 \%\end{array}$

This model has withstood the bear market up to mid-2002. Then it lost ground relative to the benchmark. It subsequently bounced back in 2003, and gained more than proportionally relative to the $S \& P 500$ following the recovery of the technology sectors that took place in early 2003. In fact, at the end of the test (September $18^{\text {th }}$ ) this model held positions in 5 technology funds (Developing Communications $+19 \%$, Technology $+10 \%$, Networking $+13 \%$, Computers $+11 \%$, Wireless $-1 \%$ ).

This set of simulations also shows how one can limit the length of the underperformance period of his/her own investments by increasing the number of funds to 10, despite a lower total return. Figure 6 shows the relative strength line of the equity curve calculated over the benchmark in the case of the 90/180 days MACD and 10 funds. This chart shows that the over-performance is 'systematic enough' to suggest the possibility of implementing a successful long-term market neutral investment strategy (long on the strongest sectors, short on the S\&P 500).

58\% obtained by holding the Gold fund from $17^{\text {th }}$ August 2001 to $7^{\text {th }}$ May 2003. 
Figure 6 Relative strength of the equity curve of the model over the S\&P 500 following 90/180 days MACD indicator and investing in 10 funds

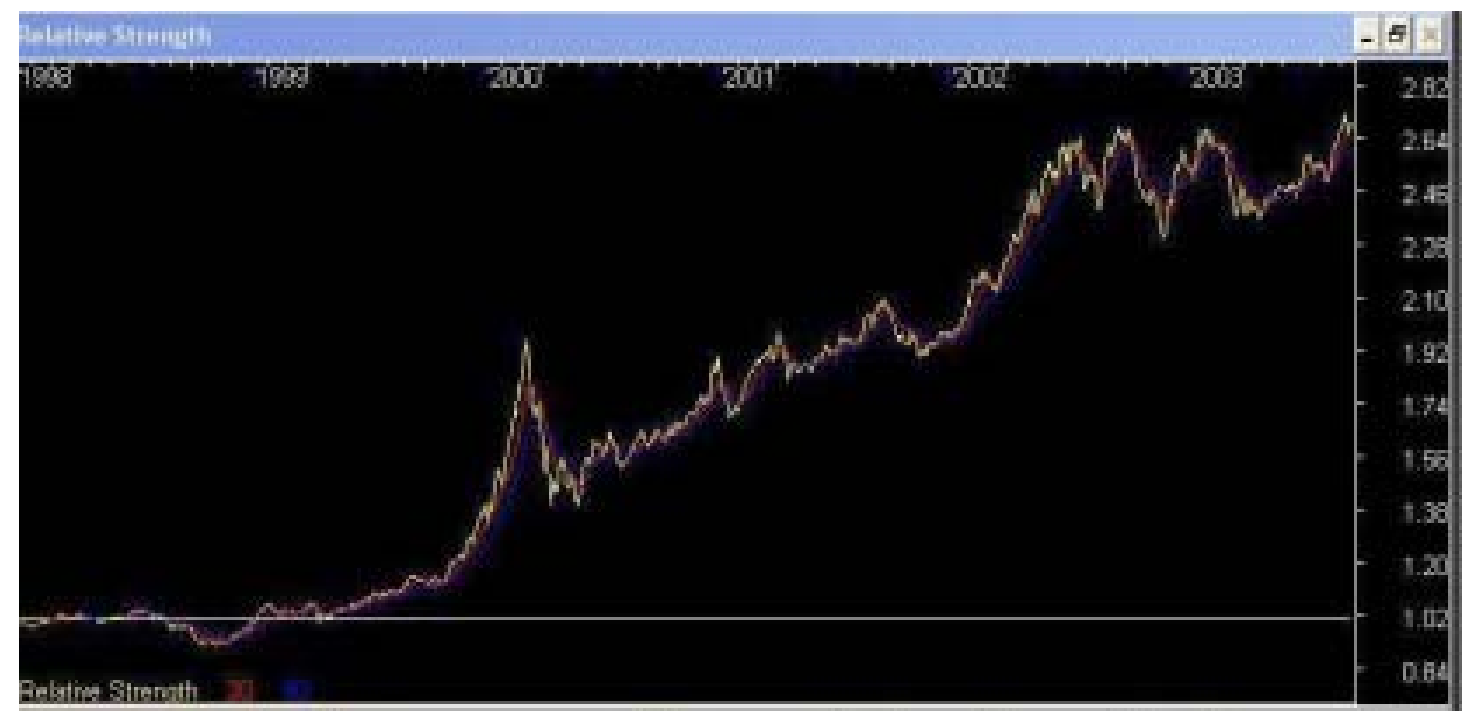

\section{Extending the simulations to include money market funds}

The next step in our exercise was to make the simulation models more reactive and flexible by adding money market funds and bond market funds. We used 14 funds of the Fidelity family, a number above the maximum allowed by our initial assumptions in order to give the models more choice. Rotation models can therefore (at least theoretically) be fully invested in cash/bond equivalents during some phases of the cycle. Investments in the money market and bond funds followed the conservative rule that, once we invested, we would hold the position for at least 30 days in order to avoid commission penalties.

The results obtained using the rate of change indicate that in general introducing money market funds leads to a more stable distribution of the returns (see Table A.1 in the Appendix), with fewer spikes in the double entry table. To illustrate the effect of introducing money market funds, consider Figures 7 and 8, which depict the total return (top chart) and the strength of the portfolio (bottom chart) relative to the S\&P 500 using the rate of change calculated in the previous 60 days, and 3 funds, respectively without and with money and bond funds. The simulation depicted in Figure 7 represents a far less regular equity curve than the one depicted in Figure 8, the second one showing lower falls in equity prices and a less erratic relative strength curve, suggesting a more consistent ability to beat the S\&P 500 . 
Figure 7 - Total return and relative strength of a rotation model based on the Rate of Change indicator (60 days), 3 sector funds and NO money market/bond funds

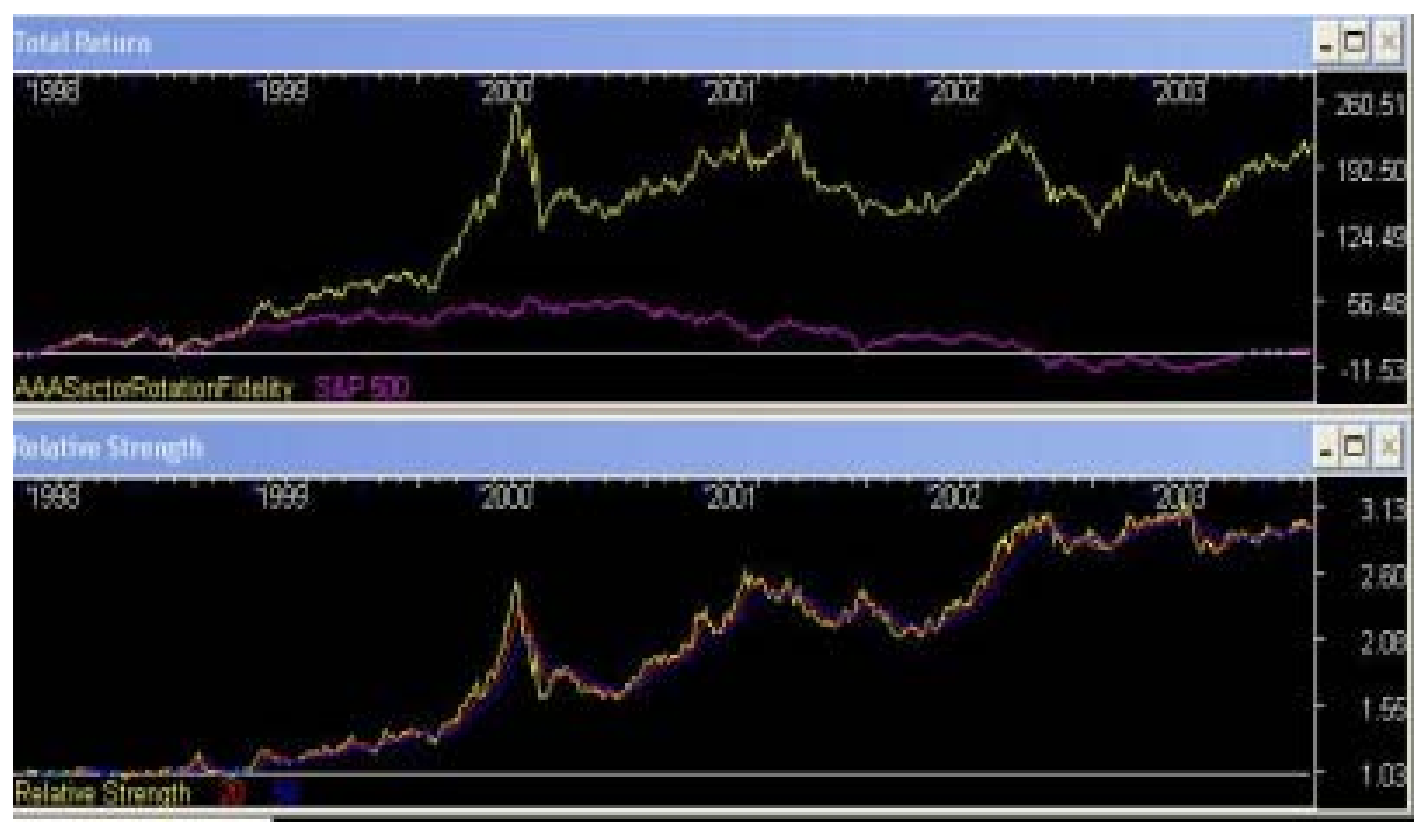

Figure 8 - Total return and relative strength of a rotation model based on the Rate of Change indicator (60 days), 3 sector funds and WITH money market/bond funds

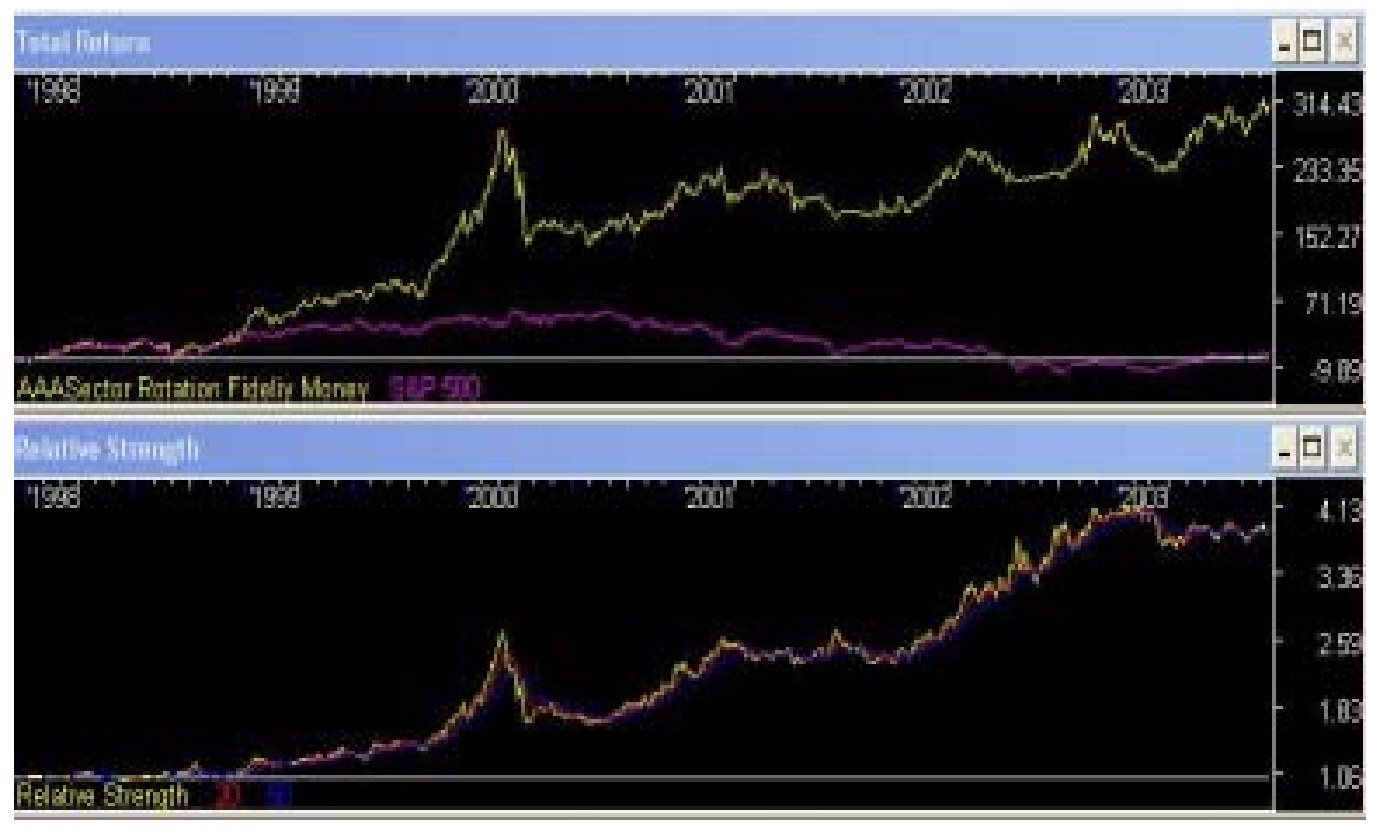


The NAV of this second model is clearly at new highs while the S\&P 500 is just over its 2003 low. The addition of money market funds has improved the performance of the simulation using the Rate of Change indicator thanks to the buffer effect carried out by the money market funds during the downturns of the market.

The results obtained using the Alpha indicator and money market/bond funds are mixed (see Table A.2). In some cases the total returns are higher than those obtained without money market funds. In others, they are lower. However, for some of the top performing results of Table 2, the addition of money market funds improves also the performance based on the Alpha indicator.

Finally, the selection of sector and money market funds based on the MACD reveals that the use of money market funds reduces the absolute performance of the model (see Table A.3). This could be due to the fact that this index is slower in recognising changes in the ranking of funds and hence does not exploit the possibility of 'parking' the investments in cash equivalent investments during downturns.

The simulations where investing in money market/bond funds was possible have shown that, during severe downturns, sector rotation could be put 'on hold' and the portfolio be invested in cash/bond equivalents, whilst sector rotations enhances the returns on a rising stock market. An interesting pattern that needs further investigation is that the slower the indicator on which sector rotation is based, the wider the suggested diversification to reduce volatility, at the cost of lower returns. All the indicators used in the simulations are measures of strength and all have confirmed the possibility of outperforming the S\&P 500 in the long-run trough simple rotation strategies over a wide range of time frames, indicators and number of funds invested. These results appear to exclude the presence of serious overfitting of the models. The results obtained can be also defined as 'robust' based on the definition given by Pardo [1992]: (1) profits over a wide range of variables (see again Figure 5), (2) profits over a wide range of market types and conditions, (3) profits over a wide range of markets, where "profits" in our case stands for "over-performance relative to the benchmark". Normally the returns obtained have shown an initial tendency to rise as the number of the funds selected was increased. If diversification reduces volatility it may be possible that one could obtain higher returns as diversification is raised. 
To test further the robustness of our results, we carried out a simple counter-check using funds of the Rydex family, which includes 16 sector funds and 4 other equity funds, and only the MACD indicator. The results are presented in Table 4 and Figure 9. The results confirm the emergence of a pattern between the volatility profile of the funds and the strategy time horizon. In particular, the higher the volatility of the fund, the longer term the indicator used to capture relative strength should be to avoid noise and confused short-term signals.

Table 4 - Total return of a rotation model based on the Moving Average Convergence Divergence indicator on Relative Strength of 20 funds of the Rydex family (slower moving average $=180$ days)

\begin{tabular}{cccc}
$\begin{array}{c}\text { Number } \\
\text { of funds }\end{array}$ & $\begin{array}{c}\mathbf{3 0} \text { days } \\
\text { Rel.Str. }\end{array}$ & $\begin{array}{c}\mathbf{6 0} \text { days } \\
\text { Rel.Str. }\end{array}$ & $\begin{array}{r}\mathbf{9 0} \text { days } \\
\text { Rel.Str. }\end{array}$ \\
\hline 1 & $113 \%$ & $54 \%$ & $63 \%$ \\
2 & $118 \%$ & $149 \%$ & $114 \%$ \\
3 & $125 \%$ & $\mathbf{2 1 4} \%$ & $152 \%$ \\
4 & $133 \%$ & $204 \%$ & $209 \%$ \\
5 & $136 \%$ & $152 \%$ & $119 \%$ \\
6 & $140 \%$ & $120 \%$ & $115 \%$ \\
7 & $128 \%$ & $110 \%$ & $103 \%$ \\
8 & $103 \%$ & $77 \%$ & $77 \%$ \\
9 & $52 \%$ & $56 \%$ & $65 \%$ \\
10 & $56 \%$ & $78 \%$ & $73 \%$
\end{tabular}


Figure 9 - Total return and relative strength of a sector rotation model based on the MACD indicator on Relative Strength of 20 funds of the Rydex family (slower moving average $=\mathbf{1 8 0}$ days)

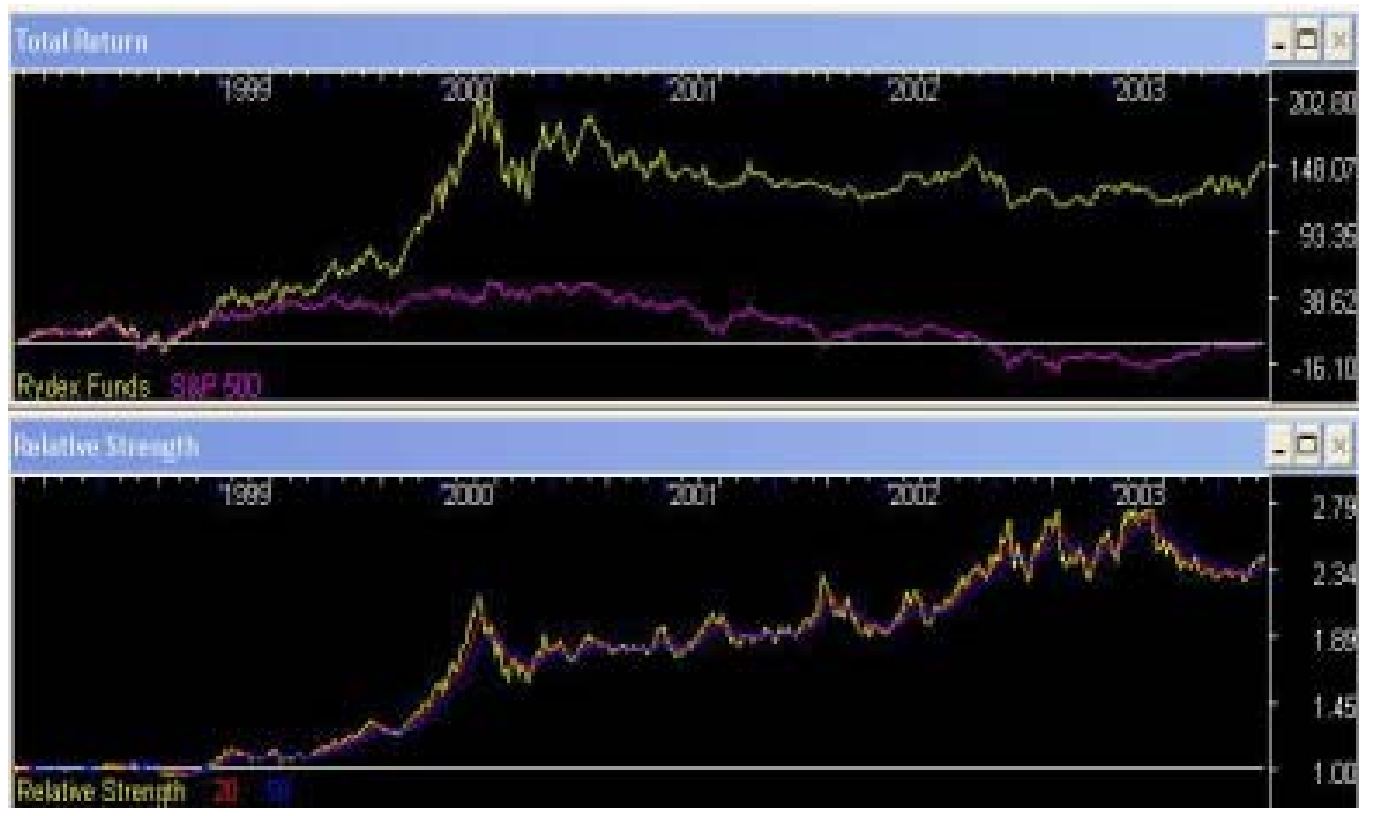

Figure 10 - Distribution of total returns of the sector rotation model based on the MACD indicator on Relative Strength of 20 funds of the Rydex family (slower moving average $=180$ days)

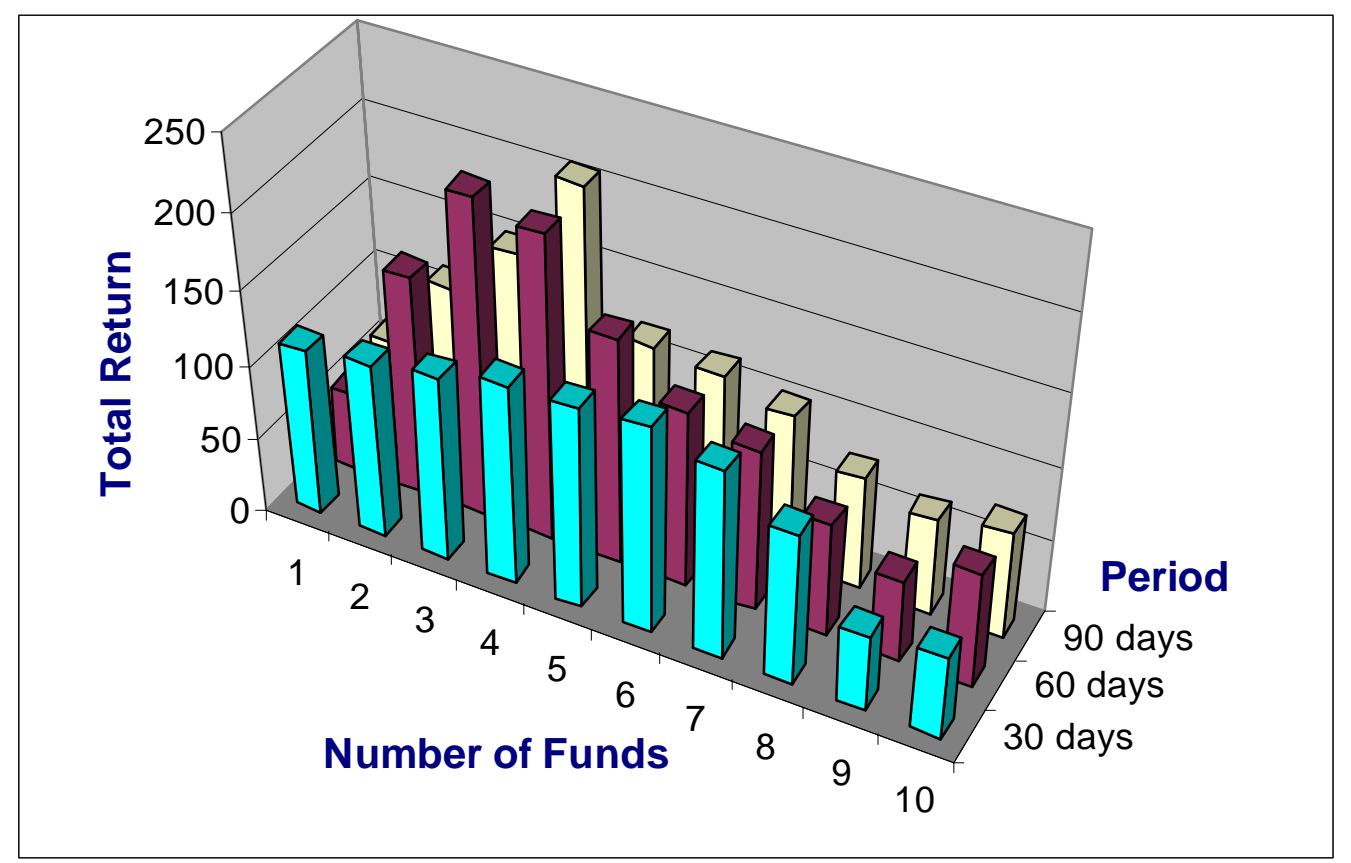




\section{Concluding remarks}

We believe that these preliminary results indicate that more attention ought to be paid to sector rotation as a technique for dynamic asset allocation, as simple techniques of systematic sector rotation seem to consistently outperform the benchmark in the longrun. As a matter of principle, this result should not be surprising. Following the research of Brinson, Hood and Beebower [1986] and the subsequent literature, asset allocation is by far the most important component in portfolio returns: dynamic asset allocation seems to strengthen this conclusion.

We also believe that a significant portion of this performance success in real investment practice can be attributed to the 'systematic' side of the strategy, rather than the sole 'sector' component. In particular, we have seen that some single trades on sector funds provided by the described strategies have been highly successful and wonder whether a discretionary portfolio manager could have done the same. The relative ease with which sector rotation has outperformed the S\&P 500 in our simulations should be viewed in the context of the well know difficulty in which institutional investment funds try to beat their benchmarks using stock picking techniques. On the other hand, these simulations indicate that sector rotation can overperform a benchmark only in the medium-long term, hence suggesting that it is a technique more adaptable for investors with a long-term horizon. 


\section{References}

Brinson, Hood, Beebower, (1986). "Determinants of Portfolio Performance", Financial Analyst Journal, July/August

Fowler, S. (1997). “Asset Allocation: Too Important to Be Left to Money Managers", Professional Investor, February.

Harloff, G. (1998). "Dynamic Asset Allocation: Beyond Buy and Hold", Stocks and Commodities, January.

King, M., Oscar, S. and Guo, B. (2002). "Passive Momentum Asset Allocation", The Journal of Wealth Management, Winter.

Pardo, R. (1992). Design, Testing, and Optimization of Trading Systems, New York: Wiley.

Schwager, J. (1992). The New Market Wizards, New York: Harper Business.

Stovall, S. (1996). Sector Investing, New York: McGraw Hill. 


\section{Appendix}

Table A.1 - Total return of a sector rotation strategy based on the Rate of Change indicator with money market funds

$\begin{array}{cccc}\begin{array}{c}\text { Number } \\ \text { of funds }\end{array} & \begin{array}{c}\mathbf{3 0} \text { days } \\ \text { R.o.C. }\end{array} & \begin{array}{c}\mathbf{6 0} \text { days } \\ \text { R.o.C. }\end{array} & \begin{array}{c}\mathbf{9 0} \text { days } \\ \text { R.o.C. }\end{array} \\ & & & \\ 1 & 105 \% & 74 \% & 8 \% \\ 2 & 142 \% & 170 \% & 65 \% \\ 3 & 66 \% & 311 \% & 76 \% \\ 4 & 48 \% & 282 \% & 83 \% \\ 5 & 87 \% & 164 \% & 134 \% \\ 6 & 67 \% & 197 \% & 101 \% \\ 7 & 66 \% & 177 \% & 85 \% \\ 8 & 76 \% & 121 \% & 89 \% \\ 9 & 80 \% & 133 \% & 81 \% \\ 10 & 70 \% & 143 \% & 81 \%\end{array}$

Table A.2 - Total return of a sector rotation strategy based on the Alpha indicator with money market funds

\begin{tabular}{cccc}
$\begin{array}{c}\text { Number } \\
\text { of funds }\end{array}$ & $\begin{array}{c}\mathbf{3 0} \text { days } \\
\text { Alpha }\end{array}$ & $\begin{array}{c}\mathbf{6 0} \text { days } \\
\text { Alpha }\end{array}$ & $\begin{array}{c}\mathbf{9 0} \text { days } \\
\text { Alpha }\end{array}$ \\
\hline 1 & $17 \%$ & $219 \%$ & $77 \%$ \\
2 & $60 \%$ & $97 \%$ & $62 \%$ \\
3 & $49 \%$ & $183 \%$ & $63 \%$ \\
4 & $99 \%$ & $253 \%$ & $111 \%$ \\
5 & $113 \%$ & $162 \%$ & $173 \%$ \\
6 & $117 \%$ & $127 \%$ & $131 \%$ \\
7 & $106 \%$ & $138 \%$ & $119 \%$ \\
8 & $134 \%$ & $86 \%$ & $136 \%$ \\
9 & $99 \%$ & $77 \%$ & $119 \%$ \\
10 & $120 \%$ & $74 \%$ & $109 \%$
\end{tabular}


Table A.3 - Total return of a sector rotation strategy based on the Moving Average Convergence Divergence on Relative Strength with money market funds (slower moving average $=180$ days)

\begin{tabular}{cccc}
$\begin{array}{c}\text { Number } \\
\text { of funds }\end{array}$ & $\begin{array}{c}\mathbf{3 0} \text { days } \\
\text { Rel.Str. }\end{array}$ & $\begin{array}{c}\mathbf{6 0} \text { days } \\
\text { Rel.Str. }\end{array}$ & $\begin{array}{c}\mathbf{9 0} \text { days } \\
\text { Rel.Str. }\end{array}$ \\
\hline 1 & $-1 \%$ & $71 \%$ & $131 \%$ \\
2 & $96 \%$ & $127 \%$ & $116 \%$ \\
3 & $87 \%$ & $99 \%$ & $\mathbf{1 9 8} \%$ \\
4 & $122 \%$ & $83 \%$ & $153 \%$ \\
5 & $109 \%$ & $129 \%$ & $180 \%$ \\
6 & $145 \%$ & $142 \%$ & $167 \%$ \\
7 & $152 \%$ & $177 \%$ & $146 \%$ \\
8 & $151 \%$ & $147 \%$ & $156 \%$ \\
9 & $118 \%$ & $165 \%$ & $129 \%$ \\
10 & $123 \%$ & $155 \%$ & $122 \%$
\end{tabular}

